\title{
Effect of Cognitive Behavioral Therapy for Psychosis (CBTP) on Mothers of Youngsters with Cerebral Palsy
}

\author{
Norsuhaily Abu Bakar ${ }^{1, *}$, Mohammad Shaban Alsmadi ${ }^{1}$, Ibrahim Mohammad Sulaiman ${ }^{2}$ \\ ${ }^{1}$ Faculty of Applied Social Sciences, University Sultan Zainal Abidin, Terengganu, Malaysia \\ ${ }^{2}$ Faculty of Informatics and Computing, Universiti Sultan Zainal Abidin, Besut Campus, 22200, Malaysia
}

Received March 4, 2021; Revised April 16, 2021; Accepted May 16, 2021

\begin{abstract}
Cite This Paper in the following Citation Styles
(a): [1] Norsuhaily Abu Bakar, Mohammad Shaban Alsmadi, Ibrahim Mohammad Sulaiman, "Effect of Cognitive Behavioral Therapy for Psychosis (CBTP) on Mothers of Youngsters with Cerebral Palsy," Universal Journal of Public Health, Vol. 9, No. 3, pp. 113 - 119, 2021. DOI: 10.13189/ujph.2021.090302.
\end{abstract}

(b): Norsuhaily Abu Bakar, Mohammad Shaban Alsmadi, Ibrahim Mohammad Sulaiman (2021). Effect of Cognitive Behavioral Therapy for Psychosis (CBTP) on Mothers of Youngsters with Cerebral Palsy. Universal Journal of Public Health, 9(3), 113 - 119. DOI: 10.13189/ujph.2021.090302.

Copyright $\bigcirc 2021$ by authors, all rights reserved. Authors agree that this article remains permanently open access under the terms of the Creative Commons Attribution License 4.0 International License

\begin{abstract}
Cognitive Behavioral Therapy for Psychosis (CBTP) is a patient-centered talking therapy mostly concentrating on the way an individual's behaviors, emotions, and thoughts are connected. Recent literature has shown that CBTP is likely to reduce positive symptoms while improving the negative symptoms and functioning. Also, several studies suggest that the use of CBTP therapy is very effective in delaying or preventing the change to full psychosis whenever applied to persons known as being at risk of developing psychosis. Therefore, this research tends to determine the impact of CBTP on mothers of youngsters with cerebral palsy and propose the most efficient and supportive method for dealing with their stress management. Using a quasi-experimental research methodology, we obtained quantitative data to infer the results of the research. The Mann-Whitney results for CBTP was obtained and presented which illustrates a substantial difference in the pre-control and pre-experimental groups of pre-distribution. The paper on new child birth with cerebral palsy problem is the first quasi-experiment of many researches on this topic (concerning comparable variables and procedures) in numerous centuries. It highlights vital ways of sustaining the initiative is a successful intervention in Youngsters with cerebral palsy to cope with behavioral issues. The government is also suggested to have further training sessions, employ the collaborative operation as an out-of-class task, and track the process carefully.
\end{abstract}

Keywords Cerebral Palsy, Mann Whitney,
Experimental Data

\section{Introduction}

Cerebral refers to anything that has to do with the brain while Palsy refers to the problems or weakness that involve the muscles. Thus, cerebral palsy $(\mathrm{CP})$, refers to a non-progressive and the most common motor disability in childhood with incurable condition. It is caused by damage to the immature brain during infancy and affect an individual's ability to maintain balance and posture $[1,40]$. The motor dysfunction of youngsters with $\mathrm{CP}$ is more complex by the advancement of secondary impairments (SI) like hip dislocation, muscle contractures, and joint deformities [2-6]. SI have a substantial influence on restricting the involvement of Youngsters with $\mathrm{CP}$ in daily living events [7]. Nevertheless, in an act of educating children such as autism, Abu Bakar and Baijuri [8] stated that the need for a suitable tactic and skilled attitude in doing the job is imperious because progenies are hard to comprehended and be cultured. Moreover, upbringing a child is one of the most sacred gifts and a tasking endeavor that every parent face $[9,10]$. Attributing the relationships, emotions of raising a child can be stress-driven most times, but dissociating the cons from the blessings, it is most rewarding. Additionally, stress is the unconditioned reaction to stimuli as a result of alteration in one's physical, 
emotional, and psychological balance [41]. Studies of Abu Bakar et al. [11] have tried to identify the numerous causes of stress in mothers who have special needs children. These factors could result from family instability and tension, work place imbalance, financial jumbo, and excitements, health and diseases, among others. Numerous kids with $\mathrm{CP}$ don't get care of extreme debilitations, for example, discourse and taking care of challenges, and most guardians have demonstrated that psychological and social issues are not being tended to. It is eminent that youngsters with CP don't have youth training and treatment [11]. It is usually defined in a different context and domain. Based on Webster's dictionary definition, stress is "a constraining force or influence such as a physical, chemical, or emotional factor that causes bodily or mental tension and may be a factor in disease causation". Parental instability is the first point of effect once a child is born with a deformity or disability. In this case, the disability being $\mathrm{CP}$ as it affects the mothers. A study conducted by Merriam [12] is seen as a foundational study in the 1980s; in the study, 60 mothers of Youngsters born with disabilities were investigated to identify the effects of stress on the sample mothers. The study mediated stress as to facilitate the degree of coping using the external family influences, resources, and child characteristics. The study was carried out in Toronto with the most influencing variables being resources, child degree of disability and manageability attempts that aid child's daily activities, social supports, religiosity, marital status of the mother and theprofessional engagements through the supports received.

Conversely, cognitive behaviors have been very helpful in introspecting different forms of depression, anxiety, and stresses. These refers to a Behavioral Cognitive Mentoring Program in reducing Cognitive and psychological problems of the child among Mothers (CBTP) and Behavioral Cognitive Mentoring Program in reducing the Feelings of despair and frustration among Mothers (CBTFD), which includes the inculcation of several forms of behavioral and pre-listed approaches that are borrowed from some principles [13]. Hence, the task of raising Youngsters with disability brings great stress and uncommon changes $[8,14]$. According to the submission by Head. [15], raising Youngsters with such disabilities affects parenting in regards to psychological, emotional, physical and financial stress due to medications and consultations [16]. Therefore, with these large reports and summing the high number at Youngsters with disabilities, mothers have been identified to be on the receiving end. The effect of this disability procreates stress, nagging, temperaments, and other forms of stress [17]. Mothers bond through birth and nurturing of the kids make stress an embodiment. Recently, cerebral palsy (CP) is a form of disability that affects the functionality of the kids by the non-progressive development of the motor neurons and other brain functions [18]. It is defined as "a non-progressive motor impairment syndrome caused by a problem in the developing brain." This is one of the utmost disabilities found in newly born kids.

\section{Cognitive Behavioral Theory}

The cognitive-behavioral theory is researched and submitted as one of the most critically and agreed model of depression and stress management. It is believed that negative and maladaptive thoughts accumulated by irrational or dysfunctional beliefs are the central phenomenon to stress. It is chosen in this research because the reach ability was wide and it holistic approach to depression. This has the vital incorporation of learning and behavioral ingredients to cognitive theories [19]. It has recorded successes which are evident for the past two centuries to the management of stress and depression. The crises on stress handling through depression were prominently described from the learning or cognitive-behavioral models [20]. These models unanimously advanced the situation of the over-generalized retort of the depressed individual to aversive conditions.

Furthermore, researchers in line with reinforcement contingencies indicated that daily mood is negatively correlated with unpleasant events and positively correlated with pleasant events [21-23]. Deficiency in social ability and skill reinforcement also produce depression [24]. However, the cognitive-behavioral theory is one of the highest influential models of addressing depression, which believed that negative and maladaptive thoughts generated by irrational or dysfunctional beliefs are the central phenomena that lead to depression. It is chosen in this research because of its holistic approach to depression that incorporated learning, behavior, and cognitive theories. It has been documented that, for the past two centuries, the phenomena of depression were prominently described from the learning or cognitive-behavioral models. Both the models unanimously approached the problem of the overgeneralized response of the depressed person to aversive conditions. The target of cognitive-behavioral remedy for the dealing with depression is to replace irrational thoughts in hopes of encouraging a balanced and the actual perspective for stress patient. In this way, the patient can attack problems tactically and prevent further depressive relapses. Studies have been conducted to evaluate cognitive-behavioral therapy for stress (PPD) either alone or in combination with drugs and psychotherapy [25].

\section{Methodology}

\section{Research Design}

Exploratory and experimental examination was utilized in this investigation. An exploratory design considered the most suitable methodology in context of the method of the 
issue being investigated [26]. It is construes that the purpose of the exploratory methods design is to collect data and use the results to understand a research problem [27].

\section{Target Population, Sample Size and Sampling Techniques of the Study}

The target population of this study comprised all Youngsters with disability from Irbid City in Jordan. The total number of Youngsters with disability from Irbid City in Jordan is 100. Similarly, researchers used various procedures in sampling populations. It is the conditions of the study and the crucial nature of participants that determine which procedures are to be employed in the sampling population [28]. The sample size comprised 40 Youngsters with disability from Irbid City in Jordan. The group consisted of female and male Youngsters. All of the participants are Youngsters with disability from Irbid City in Jordan. Moreover, this study considered the participants based on expediency sampling technique. All the participants were Youngsters with disability.

\section{Method of Data Collection}

This investigation was directed in Jordan, and the information was gathered through a self-controlled poll where the respondents requested to finish the overview all alone. The reason for picking a self-directed poll in this investigation is that it decreases cost by killing the questioner gadget and things, for example, computer software [29].

\section{Quasi-Experimental Study}

The data of the quantitative of this study collected from the quasi- experimental study, which has three sections, pre distribution of the questionnaire, intervention or training, and delay. A quasi-experiment employed in the present study to investigate the effectiveness of CBT of the mothers of Youngsters with cerebral palsy. In this non-non-equivalent controls group quasi-experimental design used. This is a common quasi-experiment design that a pre- and post-and delay and control group.

\section{Design of the Quasi-Experimental Study}

Three sections of non-equivalent quasi-experimental study will be designed in this study as presented in the diagram below:

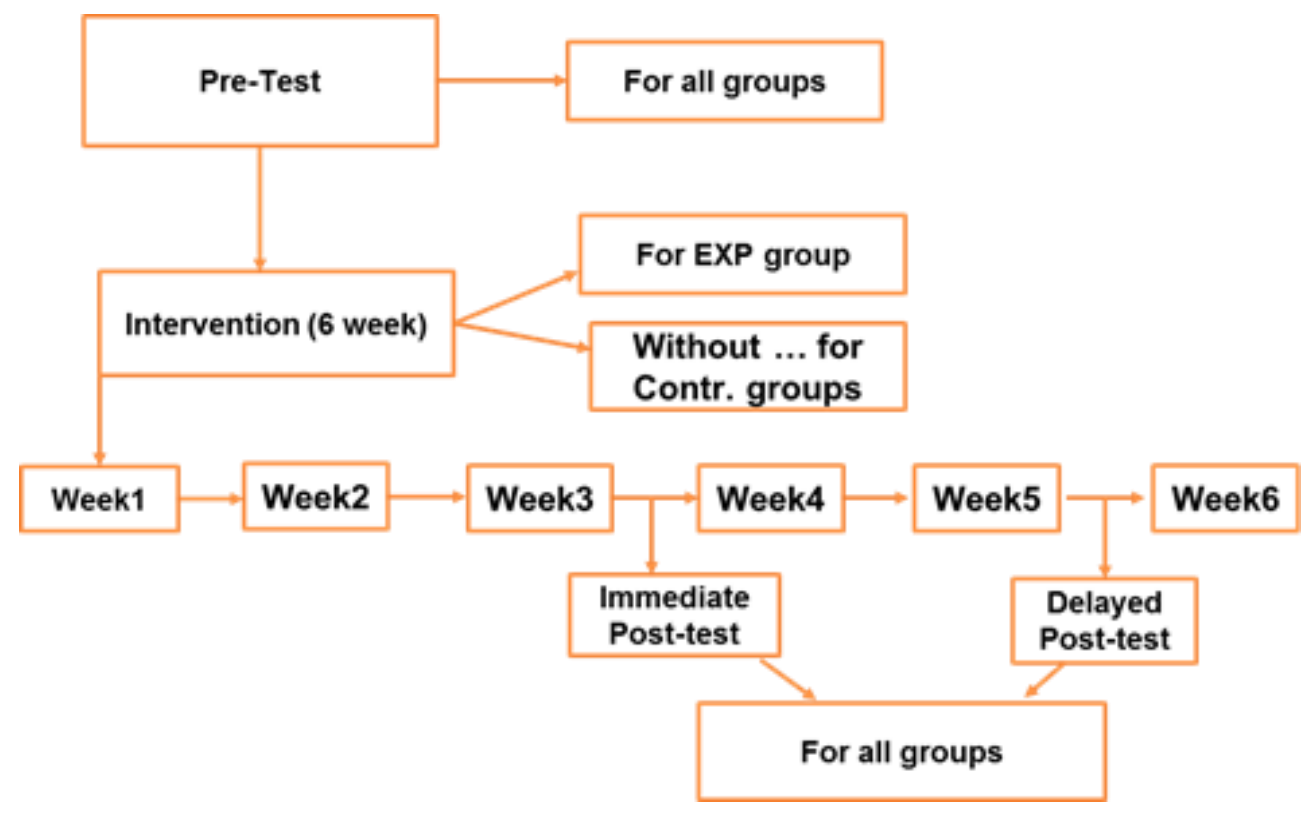

Figure 1. Quasi-Experimental Design Diagram 
This diagram represents the plow of the quasi-experimental design employed in this study. It shows the three stages of conducting the experimental studies, pre-test, intervention training, and post-test. Exp. stands for "experimental group" and Contr. Stands for "control group."

\section{Pre-Test and Post-Tests}

The first test is directed to all controlled and exploratory gatherings in the primary seven day stretch of the investigation. This is the principal phase of the semi test study. However, before the beginning of the actual study, a pilot study led to determine the legitimacy and dependability of the instrument and approve the overall method of the examination as introduced in sub-segment blow. The questionnaires were given to all groups. Meanwhile, after distributing the pre-questionnaires, a six-week intervention programmed followed. At the middle of the training period, second distributions (immediate post questionnaire) were distributed, followed by the delayed post-distribution at the end of the training. Post-distribution is the test administered to the groups after the treatment to determine the effect of the treatment on the experimental groups and to observe the causes or changes among the variables being observed [30]. The post-distribution administered twice at the middle (immediate post-distribution) and at the end of the training session (delayed post-distribution) the rationale was to ascertain the reliability of the instrument by correlating the gain scores of the participants.

\section{Validation and Reliability of the Research Instrument}

According to [31], the term validity was characterized as the level of accuracy and suitability of surmising is gathered by a scientist. It quantifies the circumstance where the instrument is intended to gauge. To meet all requirements for factor investigation, Pallant [32] proposed that the value of correlation matrix must be 0.3 or above with $\mathrm{KMO}$ of 0.6 or more and Bartlett's test must be noteworthy at $\mathrm{p}<.05$. Likewise, the specialist utilized Cronbach's Alpha to decide the unwavering quality of the exploration instrument for the quantitative perspective. Cronbach's Alpha empowers the analyst to decide how well the things identify with the build and measure the develops properly. Moreover, the researcher sent the overhauled poll to exactly 20 haphazardly chose respondents to accumulate the Pilot Study information. Utilizing the information from the Pilot Study, the scientist utilized the Exploratory Factor Analysis (EFA) to investigate and survey the dimensionality of things estimating each develops in the examination. Numerous specialists, for instance [33-37], stress that the researcher needs to utilize Exploratory Factor Analysis (EFA) strategy for each build to decide whether the dimensionality of things has transformed from the past investigation where themeasurements were created.

\section{Method of Data Analysis}

Data analysis procedure simply refers to the process and techniques employed by the researcher to scrutinize the collected data in order to extract the information from the data and give a summary description of the results based on the analysis of the data [38]. The test for normality of data distribution skewness and kurtosis were performed using SPSS to double- check if a distribution of scores significantly differed from a normal distribution. The data were sampled from a Gaussian distribution, i.e., not normally distributed data; the no-parametric test of Mann Witney was used to analyze the data collected through the questionnaire.

\section{Results and Analysis}

\section{Descriptive Statistics and Assessment of Normality}

In light of the estimation model, the investigation has analyzed the ordinariness for the things so as to survey the circulation for each thing or variable associated with the estimation model. In addition, the data characteristics of variables under study were investigated through estimation of focal inclination (mean $\left(r_{\text {avg }}\right)$ ),

$$
r_{\text {avg }}=\frac{\text { sum }}{N}
$$

and estimation of scattering (standard deviation $(\sigma)$ )

$$
\sigma=\sqrt{\frac{\sum\left(r_{i}-r_{a v g}\right)^{2}}{N-1}}
$$

In order to find the information qualities, in addition, using the Statistical Package for Social Science (SPSS) version 24.0 , the mean and standard deviation were examined. Table 1 outlines the mean and standard deviation for all indicators. Generally, the mean values for all pointers were well above 3.5. This worth showed that lion's share of the respondents in this examination were in concurrence with the inquiries. Moreover, Table 1 showed that the measures of Skewness $\left(\check{\mu}_{3}\right)$

$$
\check{\mu}_{3}=\frac{\sum_{i}^{N}\left(X_{i}-\bar{X}\right)^{3}}{(N-1) * \sigma^{3}}
$$

and Kurtosis (Kt)

$$
K t=\frac{1}{N} \frac{\sum_{i=1}^{N}\left(X_{i}-\bar{X}\right)^{4}}{\sigma^{4}}
$$

on most of the items involved in the measurement model exceeding the threshold of -2.58 and +2.58 which indicated that the data is not normally distributed as recommended by Hair et al. [39]. This reflects that the data has not satisfied the cut-off value of multivariate normality distribution. Therefore, the study can proceed for further analysis with Mann-Whitney. 
Table 1. Descriptive Statistics

\begin{tabular}{|c|c|c|c|c|}
\hline Statistics & Mean & Std. Deviation & Skewness & Kurtosis \\
\hline CBTPPRTE & 3.46 & 0.782 & 2.887 & -3.876 \\
\hline CBTPPTE & 3.89 & 0.723 & -1.334 & 2.110 \\
\hline CBTPITE & 4.23 & 0.662 & 2.335 & -4.321 \\
\hline CBTPPRTC & 4.76 & 0.367 & -3.132 & -2.543 \\
\hline CBTPPTC & 3.22 & 0.892 & -1.205 & -3.700 \\
\hline CBTPITC & 3.12 & 0.790 & 0.456 & -1.432 \\
\hline
\end{tabular}

\section{Mann-Whitney Results of CBTP}

The results are presented in Table 2, the Mann-Whitney (U) result from the response has uncovered there is a noteworthy contrast in the Pre-test and Pre- control CBTP of the pre-circulation explicitly moms of Youngsters with $\mathrm{CP}$ as the present study used. The $\mathrm{U}=33.11, \mathrm{z}=-2.778, \mathrm{p}$ $=0.000, \mathrm{r}=0.445$. By comparing the two mean ranks of experimental and control groups, it was evident also that the mean rank value of experimental group (mean rank = 66.18) was greater than the mean rank value of control group (mean rank=32.40). This clearly showed a significance difference between the two groups. The effect size of $r=-0.445$ represents a medium to large effect, thus indicating that the effect of the program was a substantive among experimental and control groups

Table 2. Between-Group among Pre-Experimental and Pre-Control CBTP

\begin{tabular}{|c|c|c|c|c|c|c|}
\hline Program & N & Mean Rank & U value & z value & P value & r value \\
\hline Pre-Experimental & 40 & 66.18 & 33.11 & -2.778 & 0.000 & $-0.445^{*}$ \\
\hline Pre-Control & 40 & 32.40 & & & & \\
\hline
\end{tabular}

Keywords: U value (Mann-Whitney), p value (positive value) r value (rate value) and $z$ value, Note: Significant at $* \mathrm{p}<0.001$.

In Table 3, the Mann-Whitney (U) result from the response has revealed there is a significant difference between the Post-experimental and Post-control CBTP of the post-distribution explicitly mothers of Youngsters with cerebral palsy as the current study used. The $U=20.21, \mathrm{z}=$ -3.888, $\mathrm{p}=0.000, \mathrm{r}=0.782$. The two mean ranks of Post-experimental and Post-control CBTP groups, also indicated that the mean rank value of Post-experimental group (mean rank $=71.32$ ) was higher than the mean rank value of Post- CBTP group (mean rank = 44.89). This confirmed that there is a significant difference between Post- experimental and Post-control CBTP groups. The effect size of $r=-0.782$ represents a large effect, hence signifying that the effect of the program was essential between Post-experimental and Post-control CBTP.

Table 3. Between-Group among Post-experimental and Post-control CBTP

\begin{tabular}{|c|c|c|c|c|c|c|}
\hline Program & N & $\begin{array}{c}\text { Mean } \\
\text { Rank }\end{array}$ & U value & z value & p value & r value \\
\hline Post-Experimental & 40 & 71.32 & 20.21 & -4.888 & 0.000 & $0.782^{*}$ \\
\hline Post-Control & 40 & 44.89 & & & & \\
\hline
\end{tabular}

Keywords: U value (Mann-Whitney), p-value (positive value) r-value (rate value) and $z$ value (), Note: Significant at $* p<0.001$.
Moreover, in Table 4, the Mann-Whitney $U$ test has indicated that there was a significant difference in the Delay-experimental and Delay-control CBTP of the immediate-distribution of questionnaires during the program $(\mathrm{U}=16.22, \mathrm{z}=-5.003, \mathrm{p}=0.000, \mathrm{r}=-0.961)$. By contrasting the two-mean rank of the program, it was additionally apparent that the mean rank estimation of the trialprogram (mean rank $=88.40$ ) was more prominent than the mean rank estimation of control program (mean rank = 53.19). This clearly exposed that the difference between groups was statistical significance. The effect size of $r=$ -0.961 represents a very large effect; therefore, demonstrating that the program was substantive between Delay-experimental and Delay-control CBTP.

Table 4. Between-Group between Delay-experimental and Delay-controlCBTP

\begin{tabular}{|c|c|c|c|c|c|c|}
\hline Group & $\mathrm{N}$ & $\begin{array}{c}\text { Mean } \\
\text { Rank }\end{array}$ & U value & z value & $\begin{array}{c}\mathrm{p}- \\
\text { value }\end{array}$ & r value \\
\hline $\begin{array}{c}\text { Delay- } \\
\text { Experimental }\end{array}$ & 40 & 88.40 & 16.22 & -6.003 & 0.000 & $0.961^{*}$ \\
\hline Delay-Control & 40 & 53.19 & & & & \\
\hline
\end{tabular}

Keywords: U value (Mann-Whitney), p value (positive value) r value (rate value) and $\mathrm{z}$ value (), Note: Significant at $* * p<0.001$.

\section{Discussion}

Youngsters with CP are at expanded danger of social and enthusiastic issues, with 1 of every 4 building up a conduct issue. This research showed that parental intervention, especially CBTP and CBTFD, is effective in addressing behavioral and emotional issues in Youngsters with CP. EBT alone has been correlated with decreases in the behavioral and emotional issues reported by parents in accordance with prior studies. In addition, RE was associated with dysfunctional parenting styles reduction. The effect sizes obtained for both pre, post and delay distribution of the questionnaires showed that the approach in increasing the Mothers of Youngsters with $\mathrm{CP}$ knowledge of both CBTP and RE were a substantive effect. This showed the government's pressing need to tackle behavioral and emotional issues in Youngsters with $\mathrm{CP}$, as well as the good fit between the requirements of education and support services and the effectiveness of parenting intervention. Ideally, parenting interventions, especially CBTP, can be translated. CBTP is intended for population-level dissemination, is readily implemented in educational or support services, is accessible in high- and low-resource areas and is accessible in many nations. Therefore, parenting interventions, such as CBTFD, should be a component of standard care for Youngsters with $\mathrm{CP}$ families. The findings indicated an extra contribution to CBTFD, with specific advantages for parenting and child hyperactivity. The combined intervention of CBTP and CBTFD, but not CBTP alone, was connected with reduced CBTP-scale child hyperactivity, parental over-reactivity, 
parental verbosity, and child behavioral issues. At six weeks of follow-up, mothers who received the combined CBTP and CBTFD intervention showed reduced childhood hyperactivity, parental laxity, and parental verbosity. compared to mothers who did not receive the training.

\section{Conclusions}

In this paper, we investigated the impact of CBTP on mothers of youngsters with cerebral palsy and proposed the efficient and supportive method for dealing with their stress management. The research considered quantitative data to achieve the above study objectives using a quasi-experimental research methodology derived quantitative data that infer the obtained results. The Mann-Whitney results for CBTP showed a substantial difference between the pre-control and pre-experimental groups of pre-distribution. Precisely, the mothers of cerebral disabled youngsters $(\mathrm{U}=33.11, \mathrm{z}=-2.778, \mathrm{p}=$ $0.000, \quad \mathrm{r}=0.445)$, the experimental and control post-experimental and post-control groups $(\mathrm{U}=20.21, \mathrm{z}=$ $-4.888, p=0.000, r=0.782$ ), and the Delay-experimental and Delay-control group of the immediate-distribution of questionnaires during the program $(\mathrm{U}=16.22, \mathrm{z}=-6.003$, $\mathrm{p}$ $=0.000, \mathrm{r}=-0.961)$. These clearly demonstrated that the mothers in the study group of youngsters with cerebral palsy performed much better than those in the control group.

\section{Acknowledgement}

The authors are grateful to the reviewers for their kind comments and suggestions.

\section{REFERENCES}

[1] Basavanthappa, B. T. Challenged Child and Nursing. In Child Health Nursing, Pp. 867-889, (2015)

[2] Abu Bakar, N, Al-Smadi, M. S., and Mohd Pauzi, H. Stress and Issues of Mental Health for Parent with Special Needs Children. International Journal of Advanced Science and Technology, 29(7 Special Issue), 471-478, (2020).

[3] Neergård, N. M. Using Computer Vision to Quantify Mirror Movements in Youngsters with Unilateral Cerebral Palsy. Master Thesis, NTNU, (2016).

[4] Fosdahl, M. A., Jahnsen, R., Kvalheim, K., and Holm, I. Stretching and Progressive Resistance Exercise in Youngsters with Cerebral Palsy: A Randomized Controlled Trial. Pediatric Physical Therapy, 31(3), 264- 271, (2019).

[5] Wright, F. V., Lam, C. Y., Mistry, B., \& Walker, J. (2018). Evaluation Of The Reliability Of The Challenge When Used To Measure Advanced Motor Skills Of Youngsters With
Cerebral Palsy. Physical \& Occupational Therapy In Pediatrics, 38(4), 382-394.

[6] Peters, C., Chang, A., Morales, A., Barnes, K., and Allegretti, A. An Integrative Review of Assessments Used in Occupational Therapy Interventions for Youngsters with Cerebral Palsy. Cadernos Brasileiros De Terapia Ocupacional, 27(1), 168-185, (2019).

[7] Lorentzen, J., Willerslev-Olsen, M., Hüche Larsen, H., Farmer, S. F., and Nielsen, J. B. Maturation of Feedforward Toe Walking Motor Program is Impaired in Youngsters with Cerebral Palsy. Brain, 142(3), 526-541, (2019).

[8] Abu Bakar, N., Baijuri, I.Z. Understanding Special education Teachers' Perspectives on Professionalism in Educating Autistic Students. International Journal of Advanced Science and Technology, 29(1), pp. 34-41, (2020).

[9] Abu Bakar, N and Al-Smadi, M. S. An Empirical Analysis of The Effectiveness of Behavioral Cognitive Mentoring: A Case Study of The Mothers of Children with Cerebral Palsy. International Journal of Academic Research in Progressive Education and Development, 8(3), 460-478, (2019).

[10] Doucet, F., Hall, M. R., and Giraud, M. Parenting Mixed-Race Youngsters. In Biracial Families. Nazarinia Roy R., Rollins A. (Eds.), Springer, Cham, Pp. 131-158, (2019).

[11] Abu Bakar, N, Al-Smadi, M. S., and Abu Hassan, M. S. N. The Effectiveness of Behavioral Cognitive Mentoring: A Model in Reducing Psychological Stress Between Mothers of Kids with Cerebral Palsy. International Journal of Psychosocial Rehabilitation, 24(6), 2550-2559, (2020).

[12] Merriam, S. Qualitative Research and Case Study: Applications in Education. San Francisco: Jossey-Bass Publishers, (1998).

[13] Puka, K., Ferro, M. A., Anderson, K. K., and Speechley, K. N. Prevalence and Trajectories of Depressive Symptoms Among Mothers of Youngsters with Newly Diagnosed Epilepsy: A Longitudinal 10-Year Study. Epilepsia, 60(2), 358-366, (2019).

[14] Rodrigues, S. A., Fontanella, B. J., De Avó, L. R., Germano, C. M., \& Melo, D. G. A Qualitative Study About Quality of Life in Brazilian Families with Youngsters Who Have Severe or Profound Intellectual Disability. Journal of Applied Research in Intellectual Disabilities, 32(2), 413-426, (2019).

[15] Head, H. Studies in Neurology. London: Oxford University Press, (1920).

[16] Biondic, D., Wiener, J., and Martinussen, R. Parental Psychopathology and Parenting Stress in Parents of Adolescents with Attention-Deficit Hyperactivity Disorder. Journal of Child and Family Studies, 28(8), 2107-2119, (2019).

[17] Miranda, A., Mira, A., Berenguer, C., Rosello, B., and Baixauli, I. Parenting Stress in Mothers of Youngsters with Autism Without Intellectual Disability. Mediation of Behavioral Problems and Coping Strategies. Frontiers in Psychology, 10, 464, (2019).

[18] Nuara, A., Avanzini, P., Rizzolatti, G., and Fabbri-Destro, M. Efficacy of a Home-Based Platform for Child-To-Child Interaction on Hand Motor Function in Unilateral Cerebral Palsy. Developmental Medicine \& Child Neurology, 61(11), 1314-1322, (2020). 
[19] Wilde, J. L., \& Dozois, D. J. (2019). A Dyadic Partner-Schema Model of Relationship Distress and Depression: Conceptual Integration of Interpersonal Theory and Cognitive-Behavioral Models. Clinical Psychology Review, 70, 13-25.

[20] Farrington, D. P. The Integrated Cognitive Antisocial Potential (ICAP) Theory: Past, Present, And Future. Journal of Developmental andLife-Course Criminology, 6, 172-187, (2019).

[21] Lennard, A. C., Scott, B. A., and Johnson, R. E. Turning Frowns (and Smiles) Upside Down: A Multilevel Examination of Surface Acting Positive and Negative Emotions on Well-Being. Journal of Applied Psychology, 104(9), 1164-1180, (2019).

[22] Van Der Stouwe, E. C., Groenewold, N. A., Bos, E. H., De Jonge, P., Wichers,M., \& Booij, S. H. (2019). How to Assess Negative Affective Reactivity to Daily Life Stress in Depressed and Nondepressed Individuals. Psychiatry Research, 279, 259-266.

[23] Rubin, L. F. (2019). Depression Moderates the Prospective Relationship Between Mood and Smoking: An Ecological Momentary Assessment Investigation. Phd Thesis, American University.

[24] Abu Bakar, N and Al-Smadi, M. S. Enhancing the Affordability of Cognitive Behavioral Therapy for Children. International Journal of Psychosocial Rehabilitation, 24(6), 2218-2231, (2020).

[25] Li, Y., and Ashkanasy, N. M. Risk Adaptation and Emotion Differentiation: An Experimental Study of Dynamic Decision- Making. Asia Pacific Journal of Management, 36(1), 219-243, (2019).

[26] Creswell, J.W and Plano, C. Designing and Conducting Mixed Method Research. California: Sage Publications, (2012).

[27] Sulaiman, I.M., Mamat, M., Waziri, M.Y., Yakubu, U.A., Maulana, M. The Performance Analysis of a New Modification of Conjugate Gradient Parameter for Unconstrained Optimization Models. Mathematics and Statistics 9(1):16-23, (2021).

[28] Drew, C., Hardman, C., and Hosp, J. Designing and Conducting Research in Education. Los Angeles: Sage Publications, (2008).

[29] Kirkpatrick, S. I., Guenther, P. M., Douglass, D., Zimmerman, T., Kahle, L.L., Atoloye, A., and Durward, C. The Provision of Assistance Does Not Substantially Impact the Accuracy of 24-Hour Dietary Recalls Completed Using the Automated Self-Administered 24-H Dietary Assessment Tool Among Women with Low Incomes. Journal of Nutrition, 149(1), 114-122, (2019).

[30] Mertens, D. M. Research and Evaluation in Education and Psychology: Integrating Diversity with Quantitative, Qualitative, and Mixed Methods. California: Sage
Publications, (2014).

[31] Pallant, J. SPSS survival manual: A step by step guide to data analysis using SPSS program. 4th Edition, Allen and Unwin, Berkshire, (2011)

[32] Fraenkel, J., Wallen, N., and Hyun, H. How to Design and Evaluate Research in Education. 8th Edition, Mc Graw Hill, (2015).

[33] Hoque, A. S. M. M., and Awang, Z. Does Gender Difference Play Moderating Role in The Relationship Between Entrepreneurial Marketing and Bangladeshi SME Performance? Accounting, 5(1), 35- 52, (2018).

[34] Hoque, A. S. M. M., Siddiqui, B. A., Awang, Z. B., and Baharu, S. M. A. T. Exploratory Factor Analysis of Entrepreneurial Orientation in The Context of Bangladesh Small and Medium Entreprises (Smes). European Journal of Management and Marketing Studies, 3(2), 81-94, (2018).

[35] Hoque, A.S.M.M, Awang, Z., Jusoff, K., Salleh, F., and Muda, H. Social Business Efficiency: Instrument Development and Validation Procedure Using Structural Equation Modelling. International Business Management, 11(1), 222-231, (2018).

[36] Noor, N. M., Aziz, A. A., Mostapa, M. R., \& Awang, Z. Validation of the Malay Version of The Inventory of Functional Status After Childbirth Questionnaire. Biomed Research International, 2015, 1-10, (2015).

[37] Yahaya, T., Idris, K., Suandi, T., \& Ismail, I. (2018). Adapting Instruments and Modifying Statements: The Confirmation Method for The Inventory and Model For Information Sharing Behavior Using Social Media. Management Science Letters, 8(5), 271-282.

[38] Nwana O. C. Introduction to Educational Research for Student Teachers. Ibadan: Heinemann Educational Books, Ltd, (1981).

[39] Hair, J., Sarstedt, M., Hopkins, L Partial Least Squares Structural Equation Modelling (PLS-SEM): An emerging Tool for Business Research. European Business Review. 26(2):106-121, (2014).

[40] Fadilah Umar, Sapta Kunta Purnama , Mohammad Furqon Hidayatullah, Jumintono, Yulingga Nanda Hanief , Sri Sumarni , Intan Suraya Ellyas, Ulfa Fatahara Laras Fadian, "Increasing Speed and Agility of Cerebral Palsy Football Indonesian Player with UMAC-CPF Exercise Model," International Journal of Human Movement and Sports Sciences, Vol. 8, No. 6, pp. 329 - 336, 2020. DOI: 10.13189/saj.2020.080604

[41] Sossou Justin Adanmavokin, Sossou Gilles Armand, Igué Babatounde Charlemagne, Ouendo Edgard-Marius, "Application of the WHO Method of Workload Indicators of Staffing Needs to Evaluate Health Workers Availability and Capacity for Universal Health Coverage in Maternal and Child Health in Benin," Universal Journal of Public Health, Vol. 8, No. 5, pp. 163 - 178, 2020. DOI: 10.13189/ujph.2020.080502. 